\title{
Oxygen Diffusion in Pure and Doped ZnO
}

\author{
Antônio Claret Soares Sabionia*, Marcelo José Ferreira Ramos ${ }^{\mathrm{a}}$, Wilmar Barbosa Ferraz \\ ${ }^{a}$ Laboratório de Difusão em Materiais, Departamento de Física, \\ Universidade Federal de Ouro Preto, 35400-000 Ouro Preto - MG, Brazil \\ ${ }^{\mathrm{b}}$ Centro de Desenvolvimento da Tecnologia Nuclear - CDTN/CNEN, \\ Pampulha, Belo Horizonte - MG, Brazil
}

Received: November 11, 2001; Revised: March 24, 2003

\begin{abstract}
Oxygen diffusion coefficients in pure and doped $\mathrm{ZnO}$ polycrystals were determined by means of the gas-solid isotope exchange method using the isotope ${ }^{18} \mathrm{O}$ as oxygen tracer. The diffusion experiments were performed from 900 to $1000{ }^{\circ} \mathrm{C}$, under an oxygen pressure of $10^{5} \mathrm{~Pa}$. After the diffusion annealings, the ${ }^{18} \mathrm{O}$ diffusion profiles were determined by secondary ion mass spectrometry. The results of the experiments show that oxygen diffusion in $\mathrm{Li}$-doped $\mathrm{ZnO}$ is similar to the oxygen diffusion in pure $\mathrm{ZnO}$, while in $\mathrm{Al}$-doped $\mathrm{ZnO}$ the oxygen diffusion is enhanced in relation to that observed in pure $\mathrm{ZnO}$, in the same experimental conditions. Based on these results is proposed an interstitial mechanism for oxygen diffusion in $\mathrm{ZnO}$. Moreover, it was found that oxygen grain-boundary diffusion is ca. 3 to 4 orders of magnitude greater than oxygen volume diffusion in pure and doped $\mathrm{ZnO}$, which means that the grain-boundary is a fast path for oxygen diffusion in $\mathrm{ZnO}$.
\end{abstract}

Keywords: oxygen diffusion, zinc oxide, point defects, varistor

\section{Introduction}

The study of non-linear current-voltage characteristics of $\mathrm{ZnO}$ based varistors, as well as of its degradation in service, is of great technological importance ${ }^{1,2}$. The understanding and modelling of these phenomena need the knowledge of the defect structure in $\mathrm{ZnO}$. However, the defect chemistry in $\mathrm{ZnO}$ is not well established yet.

An important way to characterize the defect structure in materials is by means of diffusion experiments. A number of works about oxygen diffusion in $\mathrm{ZnO}$ have been performed to determine the major point defect on the oxygen sublattice, but these early studies ${ }^{3-8}$ show poor agreement about the point defect responsible for the oxygen diffusion in $\mathrm{ZnO}$. These previous works have been reviewed in Refs. 7,8.

If we take into account, for example, the two more recents works undertaken by Haneda et $a l^{7}{ }^{7}$, and by Tomlins et $a l .{ }^{8}$, using modern techniques, they show total disagreement with regard to the oxygen diffusion mechanism.

*e-mail: sabioni@iceb.ufop.br

Trabalho apresentado no I Simpósio Mineiro de Ciências dos Materiais, Ouro Preto, Novembro de 2001.
Haneda et $\mathrm{al}^{7}{ }^{7}$ working with polycrystals of pure $\mathrm{ZnO}$, and $\mathrm{ZnO}$ doped with $\mathrm{Li}$ (3000 ppm) and with $\mathrm{Al}$ (3000 ppm), between 950 and $1052{ }^{\circ} \mathrm{C}$, at an oxygen pressure of $5 \times 10^{3} \mathrm{~Pa}$, have proposed an interstitial mechanism.

On the other hand, Tomlins et al. ${ }^{8}$ have proposed a vacancy mechanism for oxygen diffusion in $\mathrm{ZnO}$, taken into account experimental results on oxygen diffusion, measured on undoped $\mathrm{ZnO}$ single crystalline samples, between 850 and $1200^{\circ} \mathrm{C}$, at an oxygen partial pressure of $10^{5} \mathrm{~Pa}$.

In order to elucidate the diffusion mechanism for oxygen diffusion in $\mathrm{ZnO}$, a few diffusion experiments have been performed in high density polycrystals of pure and doped $\mathrm{ZnO}$. The doped samples had the same aliovalent cations (Li and Al) used by Haneda et al. ${ }^{7}$, but with different impurity contents ( $500 \mathrm{ppm})$, and the diffusion experiments were performed at a different oxygen pressure $\left(10^{5} \mathrm{~Pa}\right)$.

The oxygen diffusion experiments were performed using the stable isotope ${ }^{18} \mathrm{O}$ as oxygen tracer, and secondary ion mass spectrometry (SIMS) to analyse the diffusion profiles. 


\section{Experimental Procedure}

\subsection{Material}

The $\mathrm{ZnO}$ samples were fabricated by using high-purity powder obtained from Alfa Aesar. The impurity content of the powder was less than 10 ppm (elements detected: Fe $0.1 \mathrm{ppm}$ and $\mathrm{Pb} 1 \mathrm{ppm})$. The powder was cold pressed and sintering at $1393{ }^{\circ} \mathrm{C}$, for $2 \mathrm{~h}$ in oxygen atmosphere. The $\mathrm{ZnO}$ samples doped with $\mathrm{Li}_{2} \mathrm{O}$ ( $\mathrm{Li} 500$ ppm) and $\mathrm{Al}_{2} \mathrm{O}_{3}$ (Al $500 \mathrm{ppm}$ ) were also fabricated in the same conditions of the pure $\mathrm{ZnO}$. No additive was used as powder agglomerant in the sintering experiments.

The sintered polycrystals of pure $\mathrm{ZnO}$ and $\mathrm{Al}$-doped $\mathrm{ZnO}$ had high density (>99\% of the value of the theoretical density). The sintered Li-doped $\mathrm{ZnO}$ shown an heterogenous microstructure, with dense and porous regions. In this case, the porous region was removed, and it was only used the dense part of the sample. Grain sizes were about $20 \mu \mathrm{m}$ for pure $\mathrm{ZnO}$ and $\mathrm{Al}$-doped $\mathrm{ZnO}$ and about $30 \mathrm{~mm}$ for Li-doped $\mathrm{ZnO}$.

\subsection{Diffusion experiments}

The diffusion specimens were cut with the dimensions $1 \mathrm{~mm} \times 3 \mathrm{~mm} \times 3 \mathrm{~mm}$, polished with diamond paste, and submitted to a pre-annealing in order to equilibrate the samples with the temperature and atmosphere to be used in the diffusion annealings.

Oxygen diffusion experiments were performed by means of the gas-solid isotopic exchange $\operatorname{method}^{9}$, using the isotope ${ }^{18} \mathrm{O}$ as oxygen tracer.

The diffusion annealings were performed at 900, 950 and $1000{ }^{\circ} \mathrm{C}$, in an oxygen partial pressure of $10^{5} \mathrm{~Pa}$, for the pure $\mathrm{ZnO}$. The doped samples were treated at 900 and $1000{ }^{\circ} \mathrm{C}$, in the same oxygen pressure. The experimental arrangement used in these diffusion experiments is shown in Fig. 1.

\subsection{Depth profiling by secondary ion mass spectrometry (SIMS)}

The oxygen diffusion profiles were determined by SIMS using a CAMECA apparatus at Laboratoire de Physique des Solides - CNRS/Meudon-Bellevue, France.

The SIMS analysis of the oxygen isotopes were established using a $10 \mathrm{keV} \mathrm{Cs}^{+}$ion source. The diffusion profiles of the isotope ${ }^{18} \mathrm{O}$ was determined from the signals of the negative secondary ions ${ }^{16} \mathrm{O}^{-}$and ${ }^{18} \mathrm{O}^{-}$using the expression:

$$
\mathrm{C}=\frac{\mathrm{I}\left({ }^{18} \mathrm{O}^{-}\right)}{\mathrm{I}\left({ }^{18} \mathrm{O}^{-}\right)+\mathrm{I}\left({ }^{16} \mathrm{O}^{-}\right)}
$$

The penetration depths were determined assuming a constant sputtering rate and measuring the depths of the craters by means of a profilometer Tencor.

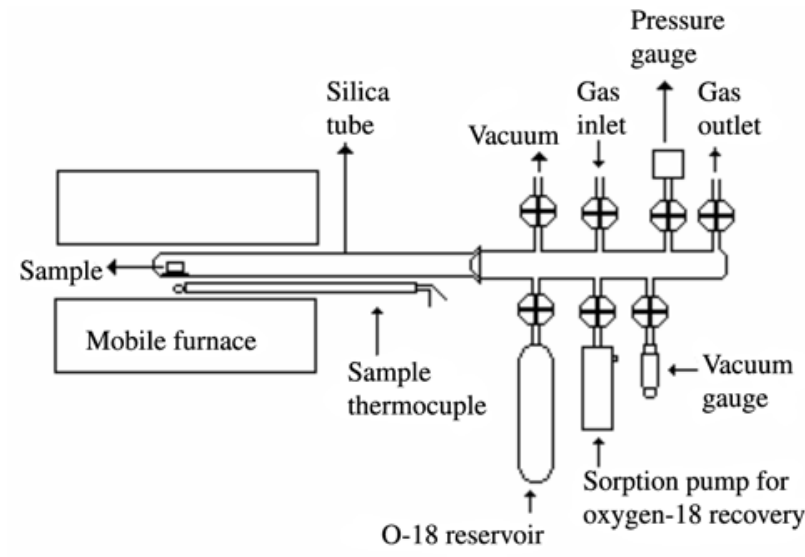

Figure 1. Schematic diagram othe heat treatment arrangement used for diffusion experiments by the isotope exchange method.

\section{Results and Discussions}

\subsection{Volume diffusion in pure and doped $\mathrm{ZnO}$}

Figure 2 shows a diffusion profile of ${ }^{18} \mathrm{O}$ in pure $\mathrm{ZnO}$, after diffusion at $900{ }^{\circ} \mathrm{C}$, for $49 \mathrm{~h}$, in an oxygen pressure of $10^{5} \mathrm{~Pa}$. The profile clearly shows two different diffusion mechanisms. The first part of the profile corresponds to the volume diffusion and the second part of profile, i.e., the tail of the profile, is a characteristic of the diffusion along the grain-boundaries ${ }^{9}$.

The volume diffusion coefficients were determined through a solution of the diffusion equation, for diffusion in a semi-infinte medium from a constant surface concentration. This solution is given by Ref. 9:

$$
\frac{C_{s}-C(x)}{C_{s}-C_{0}}=\operatorname{erf}\left(\frac{x}{2 \sqrt{D t}}\right)
$$

where $\mathrm{C}_{\mathrm{s}}$ is the concentration of the tracer at the surface, $\mathrm{C}(\mathrm{x})$ is the concentration as a function of position, $\mathrm{C}_{\mathrm{o}}$ is the natural abundance of tracer in the $\mathrm{ZnO}(0.204 \%)$, $\mathrm{x}$ is the depth, $\mathrm{D}$ is the volume diffusion coefficient, $\mathrm{t}$ is the annealing time, and erf is the error function.

The volume diffusion coefficient was determined by the fit of Eq. 2 to the part of the profile concerning the volume diffusion, as shown in Fig. 2. The same procedure was used to determine the volume diffusion coefficients in doped $\mathrm{ZnO}$.

Figure 3 shows the Arrhenius plot for the oxygen volume diffusion coefficients determined in pure and doped $\mathrm{ZnO}$. These results show that, in the experimental conditions used in this work, oxygen diffusion in $\mathrm{Li}$-doped $\mathrm{ZnO}$ is similar to oxygen diffusion in undoped $\mathrm{ZnO}$, whilst the oxygen diffusion in $\mathrm{Al}$-doped $\mathrm{ZnO}$ is greater than in pure $\mathrm{ZnO}$. 


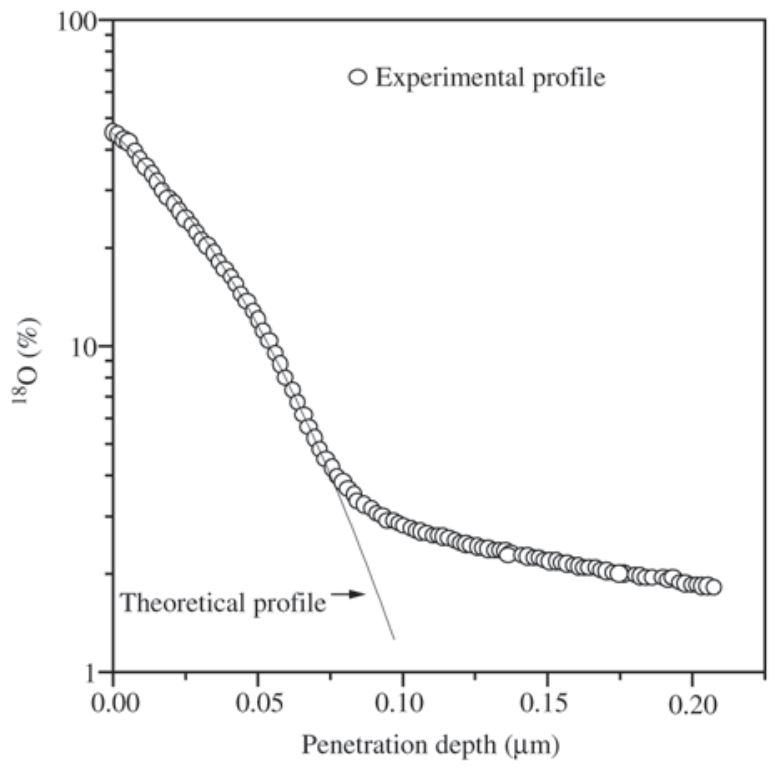

Figure 2. Concentration profile of ${ }^{18} \mathrm{O}$ in pure $\mathrm{ZnO}$ polycrystal after diffusion at $900{ }^{\circ} \mathrm{C}$.

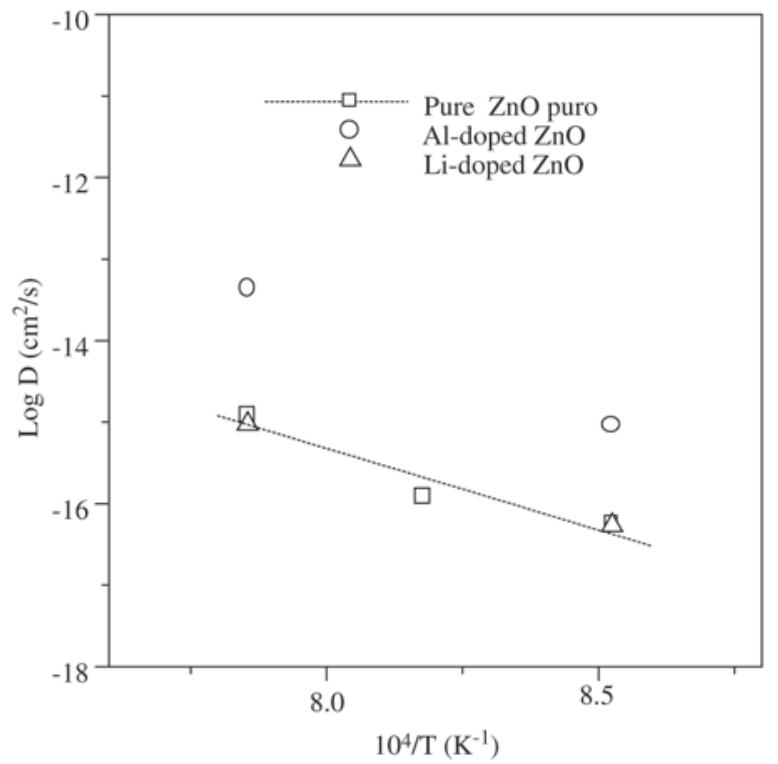

Figure 3. Arrhenius plot for ${ }^{18} \mathrm{O}$ in pure $\mathrm{ZnO}$, Li-doped $\mathrm{ZnO}$ and Al-doped $\mathrm{ZnO}$.

\subsection{Grain-boundary diffusion in pure and doped $\mathrm{ZnO}$}

The kinetics of the grain-boundary diffusion, in our experimental conditions, is of B-type, which is defined by the Harrison's conditions given by ${ }^{10}$ :

$$
\delta<(\mathrm{Dt})^{1 / 2}<\phi / 2
$$

where $\delta$ is the grain-boundary width, D is the volume diffusion coefficient and $\phi$ is the grain size.

For B-type intergranular diffusion, it is not possible to measure directly the grain-boundary diffusion coefficient. However, Le Claire ${ }^{11}$ has shown that it is possible to determine the product D' $\delta$, where D' is the grain-boundary diffusion coefficient, through the following relationship:

$$
\mathrm{D}^{\prime} \delta=0.661\left(-\frac{\partial(\ln C)}{\partial \mathrm{x}^{6 / 5}}\right)^{-5 / 3}\left(\frac{4 \mathrm{D}}{\mathrm{t}}\right)^{1 / 2}
$$

In Eq. 4, D is the volume diffusion coefficient, $\mathrm{t}$ is the diffusion time, and the gradient $\partial(\ln C) / \partial x^{6 / 5}$ is calculated from the tail of the diffusion profile in a plot of $\operatorname{lnC}$ versus $\mathrm{x}^{6 / 5}$, as shown in Fig. 4, for oxygen diffusion at $900{ }^{\circ} \mathrm{C}$. Equation 4 is valid if the parameter $\beta$, defined by:

$$
\beta=\frac{\mathrm{D}^{\prime}}{\mathrm{D}} \frac{\delta / 2}{(\mathrm{Dt})^{1 / 2}}
$$

is greater than ten.

The experimental conditions and the results obtained for oxygen grain-boundary diffusion coefficients in pure and doped $\mathrm{ZnO}$ are listed in Table 1. The values of $\mathrm{D}$ used in Eq. 4 are those previously determined in item 3.1.

Figure 5 shows a comparison of the grain-boundary diffusion coefficients measured in doped and pure $\mathrm{ZnO}$. Such as observed for the volume diffusion, in pure and Li-doped $\mathrm{ZnO}$ the grain boundary diffusion is not different, while in $\mathrm{Al}$-doped $\mathrm{ZnO}$ the grain-boundary diffusion is greater than in pure $\mathrm{ZnO}$.

Assuming for $\delta$ a typical value ${ }^{12}$ of $1 \mathrm{~nm}$, it is shown in Table 1, that the oxygen grain-boundary diffusion (D') is between three and four orders of magnitude greater than the volume diffusion (D), in the same experimental conditions. These results show that grain-boundaries are fast ways for the oxygen diffusion in polycrystalline zinc oxide.

\subsection{Diffusion mechanism}

According to Figs. 3 and 5, oxygen diffusion in pure and $\mathrm{Li}$-doped $\mathrm{ZnO}$ is similar, whilst the oxygen diffusion in $\mathrm{Al}$-doped $\mathrm{ZnO}$ is greater than in pure $\mathrm{ZnO}$.

In order to explain these results, equations describing the incorporation of $\mathrm{Li}$ and $\mathrm{Al}$ into $\mathrm{ZnO}$ structure must be writen. These equations will be writen using Kröger and Vink's notation ${ }^{13}$, and assuming the different possibilities of incorporation of the impurities in the $\mathrm{ZnO}$ structure, i.e., the cation impurities may occupy a regular site of the $\mathrm{Zn}^{2+}$, or an interstitial site, or still both positions simultaneously, as follows:

$$
\mathrm{Li}_{2} \mathrm{O} \stackrel{\mathrm{ZnO}}{\rightarrow} 2 \mathrm{Li}_{\mathrm{Zn}}^{\prime}+\mathrm{O}_{\mathrm{o}}^{\mathrm{x}}+\mathrm{V}_{\mathrm{o}}^{*}
$$




$$
\begin{aligned}
& \mathrm{Li}_{2} \mathrm{O}+\mathrm{O}_{\mathrm{i}}^{\prime \prime} \stackrel{\mathrm{ZnO}}{\rightarrow} 2 \mathrm{Li}_{\mathrm{Zn}}^{\prime}+2 \mathrm{O}_{\mathrm{o}}^{\mathrm{x}} \\
& \mathrm{Li}_{2} \mathrm{O} \stackrel{\mathrm{ZnO}}{\rightarrow} 2 \mathrm{Li}_{\mathrm{i}}+\mathrm{O}_{\mathrm{i}}^{\prime \prime} \\
& \mathrm{Li}_{2} \mathrm{O} \stackrel{\mathrm{ZnO}}{\rightarrow} \mathrm{Li}_{\mathrm{Zn}}^{\prime}+\mathrm{Li}_{\mathrm{i}}+\mathrm{O}_{\mathrm{O}}^{\mathrm{x}} \\
& \mathrm{Al}_{2} \mathrm{O}_{3}+\mathrm{V}_{\mathrm{o}}^{*} \stackrel{\mathrm{ZnO}}{\rightarrow} 2 \mathrm{Al}_{\mathrm{Zn}}+3 \mathrm{O}_{\mathrm{o}}^{\mathrm{x}} \\
& \mathrm{Al}_{2} \mathrm{O}_{3} \stackrel{\mathrm{ZnO}}{\rightarrow} 2 \mathrm{Al}_{\mathrm{Zn}}+2 \mathrm{O}_{\mathrm{o}}^{\mathrm{x}}+\mathrm{O}_{\mathrm{i}}^{\prime \prime} \\
& \mathrm{Al}_{2} \mathrm{O}_{3} \stackrel{\mathrm{ZnO}}{\rightarrow} \mathrm{Al}_{\mathrm{Zn}}+\mathrm{Al}_{\mathrm{i}}+\mathrm{O}_{\mathrm{o}}^{\mathrm{x}}+2 \mathrm{O}_{\mathrm{i}}^{\prime \prime} \\
& \mathrm{Al}_{2} \mathrm{O}_{3} \stackrel{\mathrm{ZnO}}{\rightarrow} 2 \mathrm{Al}_{\mathrm{i}}+3 \mathrm{O}_{\mathrm{i}}^{\prime \prime}
\end{aligned}
$$

Equations 5-8 describe the possible ways of incorporation of $\mathrm{Li}$ in $\mathrm{ZnO}$ structure, while Eqs. 9-12 describe the incorporation of $\mathrm{Al}$.

We will begin the discussion assuming for the oxygen diffusion a vacancy mechanism. If the vacancy is a doubly charged vacancy $\left(\mathrm{V}_{\mathrm{o}}^{*}\right)$, then the diffusion coefficient must be proportional to the $\mathrm{V}_{\mathrm{o}}^{*}$ concentration, i.e., $\mathrm{D} \alpha\left[\mathrm{V}_{\mathrm{o}}^{*}\right]$.

In pure $\mathrm{ZnO}$, as used in this work, the vacancy is an intrinsic point defect and should be formed by the Schottky disorder given by:

$$
\text { null }=\mathrm{V}_{\mathrm{o}}^{*}+\mathrm{V}_{\mathrm{Zn}}^{\prime \prime}
$$

If the vacancy concentration is changed, the diffusion coefficient should change too. Equation 5 shows that the incorporation of $\mathrm{Li}$ increases the vacancy concentration,

Table 1. Oxygen diffusion in pure and doped $\mathrm{ZnO}$

\begin{tabular}{lcccccc}
\hline Material & $\mathrm{T}\left({ }^{\circ} \mathrm{C}\right)$ & $\mathrm{t}(\mathrm{s})$ & $\mathrm{D}\left(\mathrm{cm}^{2} / \mathrm{s}\right)$ & $\mathrm{D}{ }^{\prime} \delta\left(\mathrm{cm}^{3} / \mathrm{s}\right)$ & $\mathrm{D}^{\prime} / \mathrm{D}$ & $\beta$ \\
$\mathrm{ZnO}$ & 900 & $1.764 \times 10^{5}$ & $5.53 \times 10^{-17}$ & $2.37 \times 10^{-20}$ & $4.30 \times 10^{3}$ & 68.8 \\
$\mathrm{ZnO}$ & 950 & $8.430 \times 10^{4}$ & $1.23 \times 10^{-16}$ & $6.706 \times 10^{-20}$ & $5.45 \times 10^{3}$ & 84.6 \\
$\mathrm{ZnO}$ & 1000 & $3.060 \times 10^{4}$ & $1.13 \times 10^{-15}$ & $8.63 \times 10^{-19}$ & $7.64 \times 10^{3}$ & 65.1 \\
$\mathrm{ZnO}-\mathrm{Al}$ & 900 & $1.764 \times 10^{5}$ & $8.97 \times 10^{-16}$ & $2.70 \times 10^{-19}$ & $3.00 \times 10^{3}$ & 11.9 \\
$\mathrm{ZnO}-\mathrm{Al}$ & 1000 & $3.060 \times 10^{4}$ & $4.30 \times 10^{-14}$ & $2.64 \times 10^{-17}$ & $6.13 \times 10^{3}$ & 16.9 \\
$\mathrm{ZnO}-\mathrm{Li}$ & 900 & $1.764 \times 10^{5}$ & $5.40 \times 10^{-17}$ & $2.2 \times 10^{-19}$ & $4.07 \times 10^{3}$ & 66.0 \\
$\mathrm{ZnO}-\mathrm{Li}$ & 1000 & $3.060 \times 10^{4}$ & $9.46 \times 10^{-16}$ & $1.09 \times 10^{-18}$ & $1.14 \times 10^{3}$ & 105.9
\end{tabular}

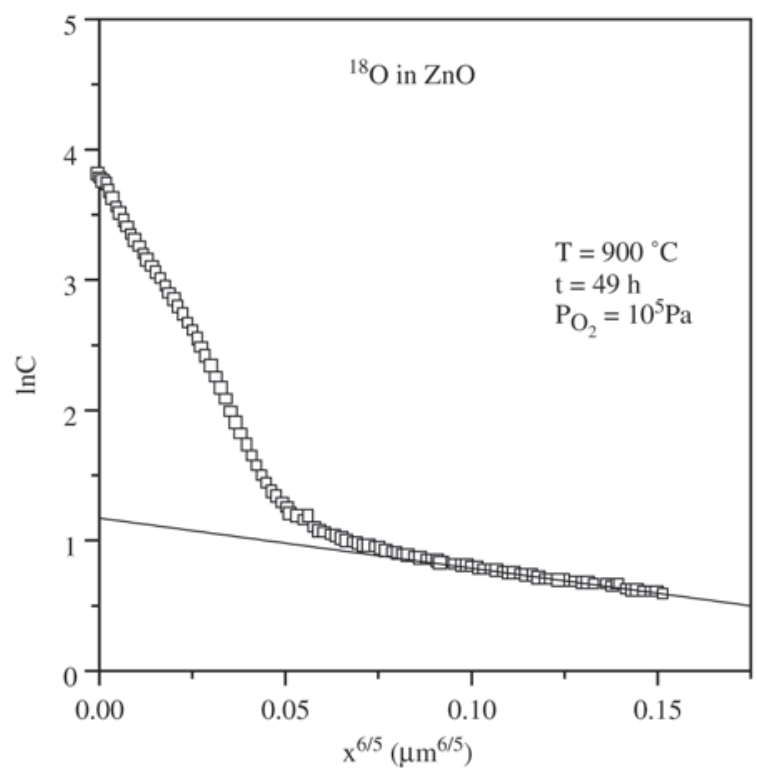

Figure 4. Oxygen concentration plot against $x^{6 / 5}$ for oxygen diffusion in pure $\mathrm{ZnO}\left(900{ }^{\circ} \mathrm{C}\right.$, oxygen pressure $\left.10^{5} \mathrm{~Pa}, 1.764 \times 10^{5} \mathrm{~s}\right)$.

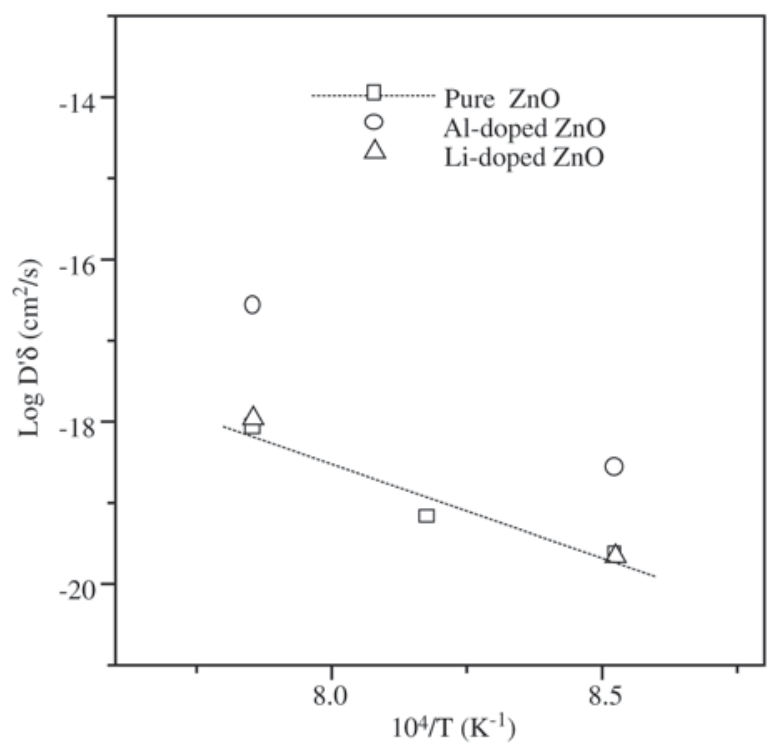

Figure 5. Comparison of the oxygen grain-boundary diffusion coefficients determined in pure and doped $\mathrm{ZnO}$. 
which should enhance the oxygen diffusion. This was not observed in $\mathrm{Li}$-doped $\mathrm{ZnO}$, in which the oxygen diffusion is similar to that in pure $\mathrm{ZnO}$.

On the other hand, Eq. 9 shows that the incorporation of Al decreases the vacancy concentration. This should decrease the diffusion coefficient, which is not supported by the diffusion experiments, which show an enhancement of the oxygen diffusion in $\mathrm{Al}$-doped $\mathrm{ZnO}$.

So, the experimental results for oxygen diffusion in pure and doped $\mathrm{ZnO}$ are not compatible with a vacancy mechanism for oxygen diffusion in $\mathrm{ZnO}$.

Lets assume now an interstitial mechanism for oxygen diffusion. In this case, the diffusion coefficient should be proportional to the interstitial oxygen, i.e., $\mathrm{D} \alpha\left[\mathrm{O}_{\mathrm{i}}^{\prime \prime}\right]$. In pure $\mathrm{ZnO}$, doubly charged interstitial oxygen $\left(\mathrm{O}_{\mathrm{i}}^{\prime \prime}\right)$ is an intrinsic point defect formed by the Frenkel disorder in the oxygen sublattice as follows:

$$
\mathrm{O}_{\mathrm{o}}^{\mathrm{x}}=\mathrm{O}_{\mathrm{i}}^{\prime \prime}+\mathrm{V}_{\mathrm{o}}^{*}
$$

Equation 6 shows that the incorporation of $\mathrm{Li}$ into $\mathrm{ZnO}$ decreases the concentration of interstitial oxygen, while Eq. 7 shows an increase of the interstiticial oxygen concentration. Both cases, described by Eqs. 6 and 7, should affect the diffusion coefficient in $\mathrm{Li}$-doped $\mathrm{ZnO}$ in regard with that in pure $\mathrm{ZnO}$, for an interstitial mechanism. However, both cases do not agree with the diffusion experiments, in which the oxygen diffusion in $\mathrm{Li}$-doped $\mathrm{ZnO}$ is similar to that in pure $\mathrm{ZnO}$.

So, Eq. 8 should describe the incorporation of $\mathrm{Li}$ into $\mathrm{ZnO}$, in the experimental conditions used, because, in this case, there is no change of the oxygen intrinsic point defects, and, consequently, no change of the oxygen diffusivity.

Equations 10-12 show different possibilities of incorporation of $\mathrm{Al}$ into $\mathrm{ZnO}$ with the formation of interstitial oxygen. So, the oxygen diffusion enhancement in Al-doped $\mathrm{ZnO}$ appears to be related to the increase of the interstitial oxygen concentration, which suggest an interstitial mechanism for oxygen diffusion in $\mathrm{ZnO}$. In such case, the incorporation of the Al should be described by one of the Eqs. 10-12.

The behaviour observed for the oxygen grain-boundary diffusion in pure and doped $\mathrm{ZnO}$ is similar to that observed for the volume diffusion, i.e., no influence of $\mathrm{Li}$, and enhancement of the diffusion in Al-doped samples. It suggests that the oxygen diffusion in $\mathrm{ZnO}$ grain-boundaries takes place by means of a mechanism similar to that of volume diffusion.

In a previous work, Haneda et co-workers ${ }^{7}$ observed that in $\mathrm{Li}$-doped $\mathrm{ZnO}$ the oxygen volume diffusion coefficients were lower than in pure $\mathrm{ZnO}$, and in $\mathrm{Al}$-doped $\mathrm{ZnO}$ the oxygen diffusion coefficients were greater than in pure $\mathrm{ZnO}$. These results of Haneda et al. ${ }^{7}$ are also consistent with an interstitial mechanism for oxygen diffusion in $\mathrm{ZnO}$.

In spite of that difference concerning the oxygen diffusion in Li-doped $\mathrm{ZnO}$, the present work and that of Haneda et al. have found no experimental evidence for oxygen diffusion in $\mathrm{ZnO}$ by means of a vacancy mechanism, and clearly show that oxygen diffusion in $\mathrm{ZnO}$ takes place by means of an interstitial mechanism.

\section{Conclusions}

- Oxygen diffusion coefficients were determined in pure and doped zinc oxide with the aim to identify the oxygen diffusion mechanism.

- Between 900 and $1000{ }^{\circ} \mathrm{C}$, under a oxygen pressure of $10^{5} \mathrm{~Pa}$, oxygen diffusion in $\mathrm{ZnO}$ grain-boundaries is ca. 3 to 4 orders of magnitude greater than volume diffusion, in the same experimental conditions. Hence the grain-boundary provides a fast path for oxygen diffusion in $\mathrm{ZnO}$.

- In our experimental conditions, oxygen volume diffusion in $\mathrm{Li}$-doped $\mathrm{ZnO}$ is similar to the oxygen volume diffusion in pure $\mathrm{ZnO}$, but oxygen volume diffusion in $\mathrm{Al}$-doped $\mathrm{ZnO}$ is greater than oxygen volume diffusion in pure $\mathrm{ZnO}$. These observations are also valid for the oxygen grain-boundary diffusion in pure $\mathrm{ZnO}$, in $\mathrm{Li}$-doped $\mathrm{ZnO}$ and in $\mathrm{Al}$-doped $\mathrm{ZnO}$. These results suggest an interstitial mechanism for oxygen diffusion in $\mathrm{ZnO}$.

\section{Acknowledgements}

This work was supported by Fundação de Amparo à Pesquisa do Estado de Minas Gerais (FAPEMIG), Brazil.

\section{References}

1. Gupta, T.K.; Carlson, W.G. A Grain-Boundary Defect Model for Instability/Stability of a ZnO Varistor.J. Mater. Sci., v. 20, p. 3487-3500, 1985.

2. Gupta, T.K. Applications of Zinc Oxide Varistors, J. Am. Ceram. Soc., v. 73, n 7, p. 1817-1840, 1990.

3. Moore, W.J.; William, E.L. Diffusion of Zinc and Oxygen in Zinc Oxide, p. 89-93. In: Crystal Imperfections and the Chemical reactivity of Solids. The Faraday Society. Aberdeen, Scotland, p. 86-93, 1959.

4. Hoffman J.W.; Lauder, I. Diffusion of Oxygen in Single Crystal Zinc Oxide. Trans. Faraday Soc., v. 66, p. 23462353, 1970.

5. Robin, R.; Cooper, A.R.; Heuer, A.H. Applications of nondestructive single-spectrum proton activation technique to study oxygen diffusion in zinc oxide. J. App. Phys., v.44, n 8, p. 3770-3777, 1973.

6. Hallwig, D. PhD Dissertation, University of Erlangen, Nürnberg, Erlangen, Germany, 1979. 
7. Haneda, H.; Sakaguchi, I.; Watanabe A.; Tanaka, J. Defect and Diffusion Forum, v. 143-147, p.1919-1224, 1997. 8. Tomlins, G.W.; Routbort J.L.; Mason, T.O. J. Am. Ceram. Soc., v. 81, n. 4, p. 869-876, 1998.

9. Philibert, J. Atom Movements, Diffusion and Mass Transport in Solids. Les Editions de Physique. Les Ulis. France. 1991
10. Harrison, L.G. Trans. Faraday Soc., v. 57, p. 1191, 1961. 11. Le Claire, A.D.; Brit. J. Appl. Phys., v. 14, p. 351, 1963. 12. Atkinson, A.; Taylor, R.I. Phil. Mag. A, v. 43, p. 979, 1981.

13. Kröger, F.A. The Chemistry of Imperfect Crystalls. North-Holland Publishing Co., Amsterdam, Netherlands, 1974. 